\section{Varying Density with Constant Rectangularity: I. Effects on Apple Tree Growth and Light Interception in Three Training Systems over Ten Years}

Cheryl R. Hampson, Harvey A. Quamme, Frank Kappel, and Robert T. Brownlee

Agriculture and Agri-Food Canada, Pacific Agri-Food Research Centre, Summerland, BC, Canada VOH $1 \mathrm{ZO}$

Additional index words. leaf area index, Malus $\times$ sylvestris var. domestica, Summerland McIntosh, Royal Gala, spur leaf area

Abstract. The effect of increasing planting density at constant rectangularity on the vegetative growth and light interception of apple [Malus xsylvestris (L) var. domestica (Borkh.) Mansf.] trees in three training systems (slender spindle, tall spindle, and Geneva $Y$ trellis) was assessed for 10 years. Five tree densities (from 1125 to 3226 trees/ha) and two cultivars (Royal Gala and Summerland McIntosh) were tested in a fully guarded split-split plot design. Planting density was the most influential factor. As tree density increased, tree size decreased, and leaf area index and light interception increased. A planting density between 1800 and 2200 trees/ha (depending on training system) was needed to achieve at least $50 \%$ light interception under the conditions of this trial. Training system altered tree height and canopy diameter, but not total scion weight. Training system began to influence light interception in the sixth leaf, when the $Y$ trellis system intercepted more light than either spindle form. Trees trained to the $\mathrm{Y}$ trellis tended to have more spurs and a lower proportion of total leaf area in shoot leaves than the other two systems. The slender and tall spindles were similar in most aspects of performance. Tall spindles did not intercept more light than slender spindles. 'Royal Gala' and 'Summerland McIntosh' trees intercepted about the same amount of light. 'Royal Gala' had greater spur leaf area per tree than 'Summerland McIntosh', but the cultivars were similar in shoot leaf area per tree and spur density.

The economics of apple [Malus $\times$ sylvestris (L) var. domestica (Borkh.) Mansf.] production have encouraged the widespread adoption of high density plantings in the past two decades. High tree density allows greater early productivity, an earlier return on capital investment, and sustained high yields of good-quality fruit (Wertheim et al., 2001). Relative to large trees, dwarf trees have a greater proportion of well-illuminated canopy, lower pesticide requirement, and higher labor efficiency. Dwarfing rootstocks such as M.9 also increase the proportion of harvested plant yield (Lakso et al., 1999; Wagenmakers, 1991a).

The high early productivity of high density plantings is partly based on their greater leaf area per unit of land area, and therefore greater interception of photosynthetically active radiation (hereafter called "light"), compared to young low density plantings (Jackson, 1989). Full-field and multi-row systems can intercept more light than single rows (Wagenmakers, 1991b; Wertheim et al., 1986), but single rows

Received for publication 16 Oct. 2002. Accepted for publication 2 June 2003. Agriculture and Agri-Food Canada contribution no. 2186. The statistical advice of John W. Hall is gratefully acknowledged. This work would not have been possible without the able technical assistance of Mark Neufield, Ron Harris, George Sajna, Brent Tiffin, Bill Whiting, other farm staff, and summer students. Special thanks to Kurt Thompson for his uncomplaining help with some tedious light readings and leaf counts. are easier to manage, permit machinery access, sometimes yield more, and have better fruit quality (Wertheim et al., 1986)

One way to increase tree density with single rows is to reduce in-row spacing. When this is done, both density and rectangularity are altered. Rectangularity (the ratio of alley width to in-row spacing) affects both interception and distribution of light, and influences yield, tree size, alternate bearing, flower density and fruit color in apple (Callesen and Wagenmakers, 1989; Cripps et al. 1975; Wagenmakers and Callesen, 1995; Wertheim, 1985). Rectangularity effects are attributed to the fact that the severity of competition depends more on the proximity of adjacent trees than density per se (Parry, 1978). Rectangularity effects can be large, e.g., $30 \%$ to $40 \%$ reduction in yield (see Parry, 1978, and references therein). A square layout $(1: 1)$ is the most favorable for light interception and distribution (Wagenmakers, 1991a; Wagenmakers and Callesen, 1995), but it cannot accommodate high tree density if tractors alleys are needed. Therefore commercial plantings use a rectangular layout.

Rectangularity is frequently ignored in investigations that compare different tree al. (1975) and Vittrup Christensen (1979) held rectangularity constant, but the latter did not prune the trees or thin the fruit, so fruit quality effects could not be assessed, and the former report covered only three cropping years. The densities and training systems. Both Cripps et adverse effects of high rectangularity (mentioned above) increase as the orchard ages and as planting density increases (Wagenmakers and Callesen, 1989, 1995).

Tree height and canopy shape also affect total interception and the penetration of light into the canopy. Training systems with angled canopies have demonstrated better light relations and productivity than slender spindles when rootstock and spacing are held constant (Hampson et al., 2002a; Robinson, 1997, 2000). Tall trees have the potential to intercept more light and yield more than short trees at the same spacing (Barritt, 2000; Callesen, 1993 Palmer, 1989; Wertheim et al., 2001).

Our objective was to determine the effect of tree density and training system on tree growth and light interception, yield, and fruit quality of apple in the absence of confounding factors such as rootstock and rectangularity. A subsidiary objective was to see whether an angled canopy with potential to intercept more light over the alley (Geneva Y trellis) could improve orchard performance relative to the spindle form (pyramid shape) commonly used in this region. Tall spindle trees were included to determine if tree height could be manipulated to advantage at a given rectangularity and density. The present report is the final one for this study. Some of the early results were outlined previously (Hampson et al., 1997, 1998). Findings on tree productivity and fruit size and color appear in a separate paper (Hampson et al., 2004).

\section{Materials and Methods}

Planting description and cultural practices The soil in this plot was a sandy loam [Naramata orthic brown soil (Wittneben, 1986] that had been planted to grapes (Vitis vinifera L.) for over 10 years previously. A green manure crop [peas (Pisum sativum L.) and oats (Avera sativa L.)] was planted and incorporated the year prior to planting, but no preplant fumigation was done. Pressure-treated support posts were installed prior to planting.

The plot was designed to keep rectangularity constant and vary density. Spacing trials require fully guarded plots to prevent border effects. The design used here is an adaptation of density trials in vegetable crops where the plots are arranged like the spokes of a wheel. The plan was based on that outlined in Pearce (1953). The modification described by Parry (1978) allows variable spacing with a reduction in the number of guard trees. Rectangularity was 2.5 between-row spacing : 1 in-row spacing throughout, so both alley width and in-row spacing changed with each successive row. Viewed from above, each block had a trapezoidal shape. The minimum in-row spacing was $1.05 \mathrm{~m}$, excluding guard rows.

The experimental design was a split-split plot with four blocks. Cultivars were assigned to main plots, training systems to subplots and densities to sub-subplots. Each sub-subplot consisted of two fully guarded experimental trees i.e. there were guard trees on both sides of each training system and each density tested. Block orientation was randomized. Training 
system and cultivar were randomized within blocks, but densities were assigned in sequential order to minimize the number of guard trees required and maximize the number of densities that could be tested within the available area. The corresponding tree densities for the experimental rows were $1125,1587,2012$, 2481, and 3226 trees/ha.

Two cultivars of 1-year-old feathered (i.e. branched) trees were used. Virus-free 'Royal Gala' trees on virus-free M.9 rootstock were grown at the Pacific Agri-Food Research Centre, Summerland 'Summerland McIntosh' on M.9 trees were grown by a commercial nursery in British Columbia, Canada. The cultivars were chosen because they differ in vigor, and both are commercially important in the region. The trees were planted in north-south rows in Spring 1992, $\approx 15 \mathrm{~cm}$ from the south side of the post with the bud union $\approx 5 \mathrm{~cm}$ above the soil line. The trees were graded before planting, with the largest, most branched ones chosen for experimental trees, and the others used as guard trees. The trunk cross-sectional area of the trees at planting ranged from $3.9-4.5 \mathrm{~cm}^{2}$.

Three training systems were used: slender spindle (SS), Geneva Y trellis (YT) and a modified vertical axis that we called "tall spindle" (TS). The SS and YT were trained as described previously (Hampson et al., 2002a), except that the final target height for the SS was $2.0 \mathrm{~m}$, and there was always at least $1.5 \mathrm{~m}$ between the top of the $\mathrm{Y}$ in adjacent rows, as recommended by Robinson et al. (1989). The TS was a combination of spindle and axis training. The terminal was pinched each June for the first 3 years to encourage lateral shoots to grow. The lower scaffolds were trained as for the vertical axis. The leader was tied to give it support and maintain dominance, and competing laterals were pinched back or removed. The posts for this system were $3.3 \mathrm{~m}$ ( $2.4 \mathrm{~m}$ above ground). The final target height for TS was $3.0 \mathrm{~m}$.

Ryegrass (Lolium perenne L.) was planted in the tractor alleys, and weed-free strips $1.5 \mathrm{~m}$ wide were maintained under the tree rows with herbicides. Foliar micronutrients, pest and disease controls were applied according to regional recommendations for commercial plantings. Fruit were hand-thinned in 3-6 weeks after bloom, aiming for single-fruit clusters $15 \mathrm{~cm}$ apart. Trees were dormant-pruned annually, removing the minimum amount of wood necessary without compromising the principles of the training system. No summer pruning was done.

Water and fertilizer were applied on a per-tree basis. The plot was irrigated annually from mid-April to mid-October. Drip emitters ( $4 \mathrm{~L} / \mathrm{h})$ were spaced on both sides of the trunk, equidistant between trees. From 1992 to 1994 the trees were watered three times per week for $4 \mathrm{~h}$ each time. By 1994, the growth of the trees in two of the four blocks was not satisfactory. A gravel ridge ran through the middle of this half of the plot. We decided to continue to water all zones the same, but to boost the water application to meet the needs of trees in the zone with poorer soil. Irrigation from 1994 through 2001 was run 2 h daily. The total water applied was 772-908 L per emitter in
1992 and 1993, and 1300-1330 L during the rest of the study. Overhead irrigation in July and August supplemented the planting during hot weather and kept the grass alive (average $10-22 \mathrm{~cm}$, depending on the year).

All trees were fertigated with $12 \mathrm{~g}$ of 20-20-20 per tree per year from irrigation startup, followed by $15.5-0-0$ at $50 \mathrm{~g}$ per tree per year. All fertigation was complete by 15 Aug. each year. In Mar. 1998, a ground application of $14-16-0$ at $90 \mathrm{~kg} \cdot \mathrm{ha}^{-1}$ was made.

Measurements and statistical analysis. The following response variables were measured annually, unless otherwise noted. Tree height, canopy spread, and trunk girth were recorded after harvest and before pruning. Trunk diameter was measured $15 \mathrm{~cm}$ above the graft union. The average of two perpendicular measurements made with digital calipers was converted to trunk cross-sectional area (TCA) prior to analysis. The maximum canopy spread was recorded as the average of measures across and along the row. Dormant season pruning weights were recorded as the sum of the two trees per sub-subplot. These weights were summed over the life of the planting and expressed as pruning weight per plot and per meter of row, except that the 1997 data were lost, and could not be included. At the end of the experiment, the total scion fresh weight was recorded. The trees were cut off at the graft union and weighed in the field.

Light interception was measured as previously described (Hampson et al., 2002a). Measurements were done in August or early September after shoot elongation ceased. Previous research has shown that the interception of light by fruit is negligible (Verheij and Verwer, 1973). Interception was measured annually starting in 1993, except for 1996, when partly cloudy weather during August-September prevented reliable measurements. In 1995 , measurements were completed for only three of the four blocks for the same reason.

Leaf and spur counts were done after harvest in 1995, 1997, 1998, and (for two blocks only and preharvest) 2001. Spurs were also counted in 1999, but not leaves. A spur was defined as a short determinate shoot $<5 \mathrm{~cm}$ long. Multiple spurs on long dards were all counted, and their leaves were included in spur leaf area samples. Separate counts and leaf area measurements were done for spur and shoot leaves, with the sampling procedure described by Kappel and Quamme (1993). From these counts and measurements we obtained total leaf area index (LAI, defined as the ratio of leaf area to orchard floor area allotted to that tree, including alleys), leaf area per tree (shoot, spur, and total), spur leaf area index, the number of spurs per tree, spur density (number of spurs/TCA), and the proportion of total leaf area comprised of shoot leaves. A total of 120 trees were sampled (one per sub-subplot). To reduce the labor requirement in later years as the trees grew, sampling protocol varied. In 1995 and 1997, half-trees (south half blocks A and C, north half blocks B and D) were sampled. After 1997, quarter trees were sampled. Data were converted to whole-tree equivalents for tabulation in this paper.
Statistical analyses were done with the SAS software package (SAS Institute, Cary N.C.). Response variables were analyzed with a mixed-model analysis of variance, with block, and interaction terms containing block, as random factors. For data collected on a subsubplot basis (i.e. light interception, pruning weights, leaf area index, and shoot and spur leaf data), cultivar effect was tested against error A (block $\times$ cultivar), system and cultivar $\times$ system were tested against error B (block $\times$ cultivar $\times$ system), and density and interaction terms for density, were tested against the residual error. All other variables were analyzed on a per tree basis. In this case errors A and B were the same, but density and interaction terms containing density were tested against error $C$ (block $\times$ cultivar $\times$ system $\times$ density) instead of the residual error. Main-effect means were separated with the Waller-Duncan Kratio $t$ test $(\mathrm{K}$ ratio $=100)$, using error $\mathrm{B}$ for system, and error $\mathrm{C}$ for density. To determine the appropriate order for equations involving responses to density, orthogonal contrasts were used. Regression equations were obtained with the SAS regression procedure REGR.

\section{Results and Discussion}

This experiment spanned 10 years and used a statistical design sensitive to small differences in plant response to different treatments. In some years and for some response variables, two- or three-way factor interactions were statistically significant. In nearly all cases, these interactions were ephemeral (i.e., occurring only once or twice during 10 years) and were due to small differences in the degree of the response to a certain combination of factors. In the following discussion, interactions are only mentioned if they occurred at least twice.

Vegetative growth. Averaged over all training systems, trees had reached their final canopy diameter by the third leaf (1994) at the two highest densities, and by 1995 for all other densities (data not shown). Final tree height was reached in 1995-96 for all densities. Thereafter, height and spread fluctuated year to year due to pruning. Averaged over all densities, spindle trees reached final canopy diameter in 1994, and YT trees 1 year later (data not shown). Target tree height was reached in 1995 for SS and 1996 for YT. The TS never reached its target height of $3.0 \mathrm{~m}$, but was taller than SS by 1995 , and reached $2.8 \mathrm{~m}$ by 1998 .

A reduction of overall tree size with increasing tree density has been reported previously (Cripps et al., 1975; Vitrup Christensen, 1979). By the end of the experiment, TCA at the highest density was $20 \%$ less than at the lowest density (Table 1). Small but statistically significant differences in TCA were present at planting. The change in TCA (final TCA - initial TCA) was therefore calculated to account for this difference, but it showed the same pattern as final TCA (Table 1). Trunk cross-sectional area is often used as a convenient nondestructive estimate of overall tree size (Barden and Marini, 2001). There was a trend for trees to be taller and narrower at high density, but the differences were nonsignificant (Table 1). Over 
Table 1. Mean final trunk cross-sectional area (TCA), change in TCA, tree height, canopy spread, final scion fresh weight, cumulative weight of prunings per plot and per meter of row length, and light interception of 'Royal Gala' and 'Summerland McIntosh' apple trees in three training systems at five tree densities after 10 years.

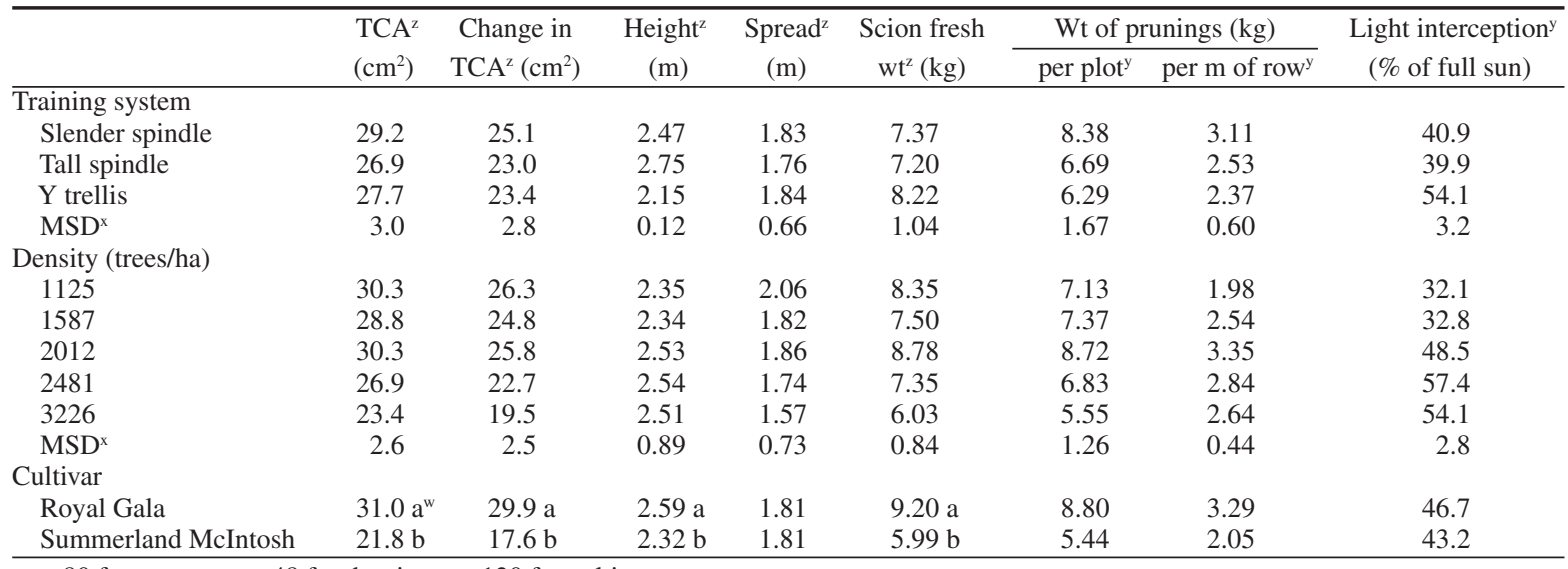

${ }^{2} \mathrm{n}=80$ for system, $\mathrm{n}=48$ for density, $\mathrm{n}=120$ for cultivar.

${ }^{y} \mathrm{n}=40$ for system, $\mathrm{n}=24$ for density, $\mathrm{n}=60$ for cultivar

${ }^{x}$ Minimum significant difference determined by Waller-Duncan $\mathrm{K}$ ratio $t$ test $(\mathrm{K}$ ratio $=100)$.

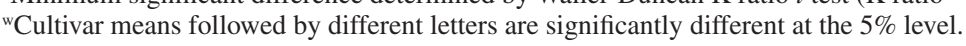

the range of density tested, the effect on height $(\approx 7 \%)$ was less than that on spread $(\approx 23 \%)$, the latter better reflecting the difference in TCA. Cripps et al. (1975) also observed that high tree density produced taller, narrower trees. The Pearson correlation coefficient was 0.91 for the relationship between scion weight and TCA in the present study.

Tree training also caused differences in tree height and spread, but overall tree size, as estimated by TCA or final scion fresh weight, was unaffected by training system (Table 1). Differences in spread were small in absolute terms $(\approx 10 \mathrm{~cm})$ and the mean separation among systems differed slightly from year to year because of pruning.

As expected, 'Gala' trees had greater TCA and final scion weight than 'McIntosh'(Table 1). 'Gala' trees were taller than 'McIntosh' trees but had similar canopy spread. 'Gala' required more pruning than 'McIntosh' (Table 1), but the difference was only statistically significant at $P=0.07$. The YT and TS had similar pruning requirements but the SS needed more containment pruning (Table 1). Clayton-Greene (1993) also found pruning weight differences among training systems, despite keeping pruning to a minimum.

Cumulative pruning weight was greatest at intermediate densities, whether calculated per plot or per $m$ of row (Table 1). One explanation may be found by comparing pruning weight per plot and TCA. At the lowest density, trees barely filled their in-row spacing. Since overall tree growth (as measured by TCA) was unaffected by density up to 2012 trees/ha, but the allotted space per tree was much less, more containment pruning was required than at the lowest density. Competition reduced overall tree size as density rose (Table 1, TCA). Relative to a density of 2012 trees/ha, this amounted to a $36 \%$ reduction in weight of wood removed per plot at the highest density, or a $21 \%$ reduction per $m$ of row. The combined effects of tree density and growth meant that the pruning requirement per plot (or per tree) was least at high density, but the pruning requirement per $m$ of row was least at low density (Table 1). The relationship between density and cumulative pruning weight per $m$ of row was quadratic, but the fit of this relationship was poor (pruning weight, $\mathrm{kg}=$ $-0.98+3.45 \times 10^{-3} \mathrm{x}-7.27 \times 10^{-7} \mathrm{x}^{2}$, where $\mathrm{x}$ $=$ density in trees per hectare; $r^{2}=0.09, \mathrm{n}=$ $120, \operatorname{Pr}>\mathrm{F}=0.03$ ).

Light interception. Interception increased annually up to 1998 (seventh leaf), but thereafter was stable (Fig. 1). In other studies (Robinson et al., 1993; Verheij and Verwer, 1973), interception continued rising until year 8 or 9 , and reached higher final values at comparable densities. Light interception averaged over the

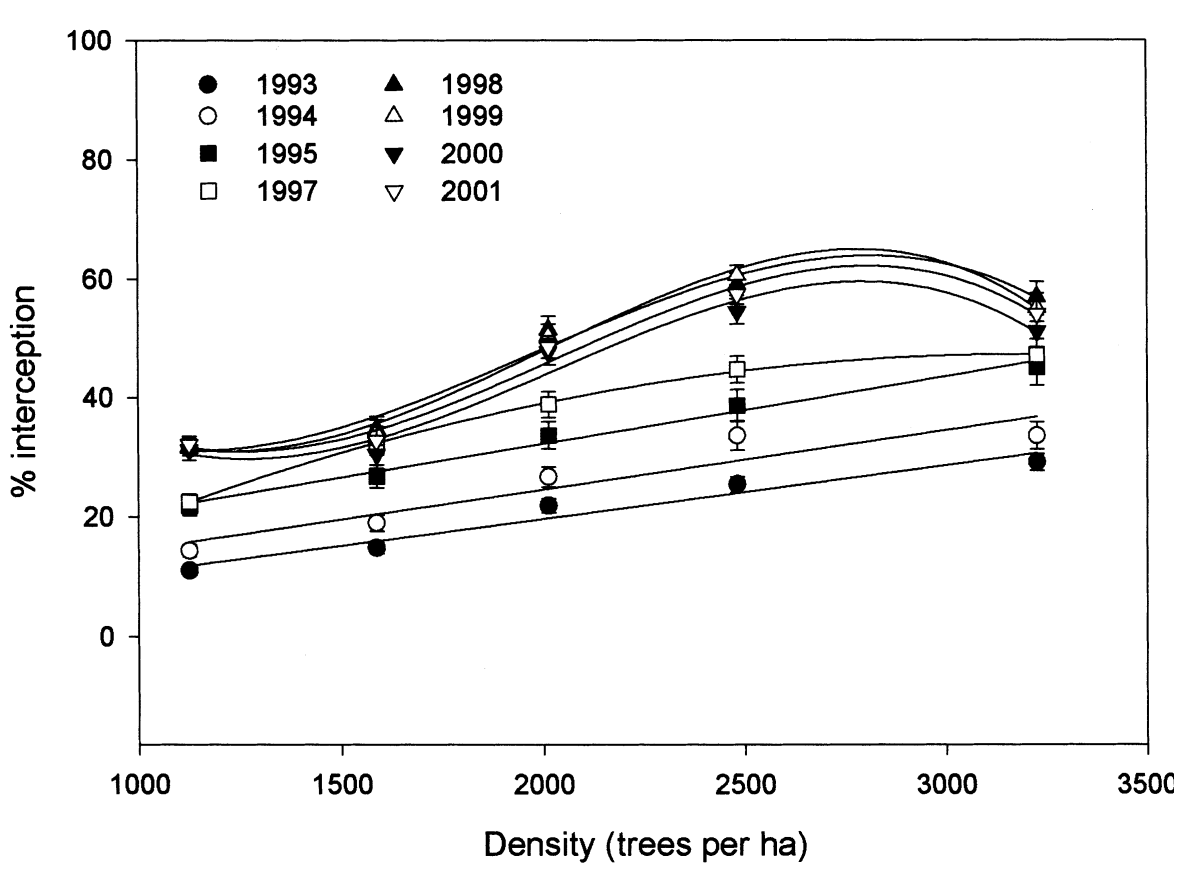

Fig. 1. Light interception (\% of full sun) at different tree densities over 8 years. Vertical bars show standard errors. Regression equations (where $\mathrm{x}=$ density in trees per ha): 1993 , interception $=1.84+8.92 \times$ $10^{-3} \mathrm{x}, r^{2}=0.57, \mathrm{n}=120 ; 1994$, interception $=4.66+9.97 \times 10^{-3} \mathrm{x}, r^{2}=0.38, \mathrm{n}=120 ; 1995$, interception $=9.57+0.011 \mathrm{x}, r^{2}=0.41, \mathrm{n}=90 ; 1997$, interception $=-12.08+0.037 \mathrm{x}-5.88 \times 10^{-6} \mathrm{x}^{2}, r^{2}=0.44(\mathrm{n}=$ 120). Equation for 1998-2001 in Fig. 2. last 4 years (Fig. 2) rose as density rose. Cultivar did not affect interception significantly (Table 1), despite the difference in vigor, perhaps because canopy spread was about the same for 'Gala' and 'McIntosh'. The YT began to intercept more light than spindle forms starting in the sixth leaf (data not shown), and at maturity, its interception was $35 \%$ greater than spindles on average (Table 1). Robinson et al. (1993), Wünsche et al. (1996) and Robinson (1997) also found the YT to intercept more light than SS.

The greater height of the TS did not improve interception relative to SS (Table 1). Taller trees usually intercept more light (Barritt, 2000;

HortScience Vol. 39(3) June 2004 


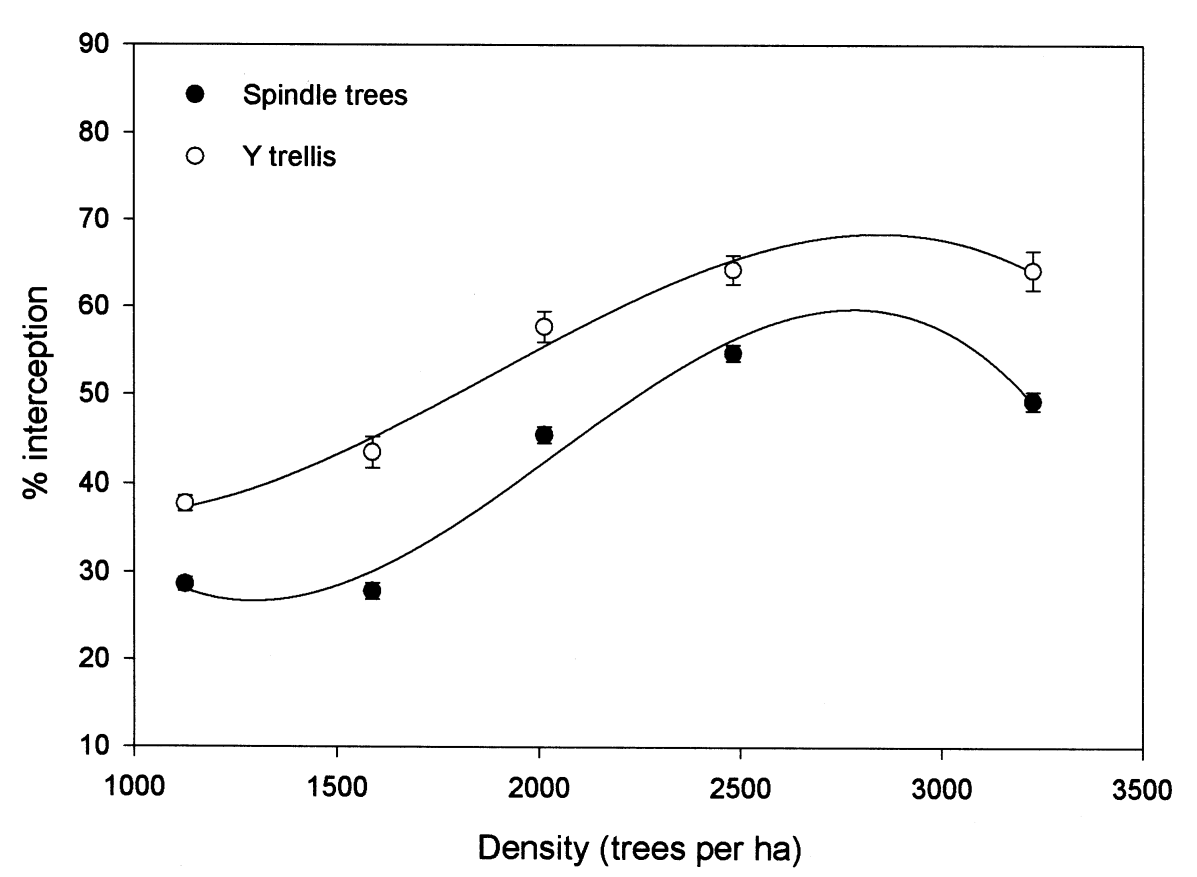

Fig. 2. Four-year average light interception (1998 to 2001 inclusive) at different tree densities for spindle and $\mathrm{Y}$-trellis tree training systems. Vertical bars show standard errors. Regression equations (where $\mathrm{x}$ $=$ density in trees per hectare) $: \mathrm{Y}$ trellis, interception $=66.49-0.073 \mathrm{x}+5.18 \times 10^{-5} \mathrm{x}^{2}-9.15 \times 10^{-9} \mathrm{x}^{3}$, $r^{2}=0.56, \mathrm{n}=160 ;$ spindles, interception $=144.47-0.22 \mathrm{x}+1.22 \times 10^{-4} \mathrm{x}^{2}-2.00 \times 10^{-8} \mathrm{x}^{3}, r^{2}=0.67$, $\mathrm{n}=320$.

Corelli and Sansavini, 1989), but not always (Callesen, 1993; Wagenmakers and Callesen, 1989). We attribute our findings to the fact that the two systems did not differ enough in height. Although our target heights for SS and TS differed by $1 \mathrm{~m}$, actual tree heights differed only by $30-40 \mathrm{~cm}$, depending on the year (Table 1). Data on spindle trees were therefore pooled (Fig. 2). Shoots were pinched in June on the TS in the first 3 years to encourage lateral branch development. Perhaps this treatment reduced final tree height. The effect of density on interception in spindle and $\mathrm{Y}$ forms was described by third-order equations (Fig. 2)

The effects of cultivar and system on light interception interacted in 1997 and 1998. In those years, the difference in light interception between the YT and the two spindle forms was greater for 'Gala' than for 'McIntosh' (data not shown). The effect disappeared subsequently. In 1999 to 2001 inclusive, the cultivar $\times$ system $\times$ density interaction was significant. Examination of the means revealed no discernible pattern to the interaction, merely small differences in the extent of response among particular treatment combinations. On average, only the YT (Table 1) attained the $50 \%$ to $70 \%$ interception considered optimal from previous research (Lakso and Robinson, 1997; Robinson, 1997; Verheij and Verwer, 1973; Wünsche and Lakso, 2000). The angled canopy intercepted more light over the alleys than the pyramidal shape. Increasing the height of the spindle form to $2.8 \mathrm{~m}$ was not enough to compensate. To boost light interception with a spindle form, it would be necessary to furthe increase either height or tree density, or to reduce alley width (increase rectangularity). Spindle trees only reached $50 \%$ interception at densities of $\approx 2250$ trees/ha or more at the age. An orchard with LAI below unity cannot intercept enough light to achieve an economic level of productivity. Trees at the two highest densities in our trial had attained a LAI of 1 by the fourth leaf (Table 2), whereas trees at the lowest density still had not reached a LAI of 1 after 10 years (data not shown).

The proportion of leaf area in shoots and spurs is of interest in view of recent data demonstrating that spur LAI and interception by spur leaves is more closely related to yield than extension shoot LAI and interception (Sansavini and Corelli Grappadelli, 1997; Wünsche et al. 1996; Wünsche and Lakso, 2000). The importance of spur leaves to early-season fruit growth in apple is also well-established (Wünsche and Lakso, 2000 and references therein). The two cultivars differed significantly in the proportion of leaf area in shoot leaves (PS) in 1995 (Table 2); in subsequent years the difference was nonsignificant, although 'McIntosh' tended to have a greater PS. The higher PS for 'McIntosh' may be a true cultivar difference, or it could be related to its greater propensity for alternate bearing, as "off" trees divert more resources into shoot growth (Wünsche and Lakso, 2000). Increasing tree density did not alter PS (Table 2). In contrast, training shoots to the YT significantly reduced the PS. The values in Table 2 are comparable to the $40 \%$ to $50 \%$ PS found by Ferree (1992) but lower than the $70 \%$ to $80 \%$ found by Sansavini and Corelli (1992). The latter authors included bourse leaves in the shoot leaf component, and we included them with spur leaves.

Spur LAI was affected by both cultivar and planting density, but system effects were not consistent. 'Gala' had a significantly higher spur LAI than 'McIntosh', a trend magnified in later years as many bourse shoots developed on 'Gala', but not 'McIntosh' (compare 1995 and 1998, Table 2). As expected, spur LAI rose as density increased. Mean spur LAI was always higher on the YT than the spindle trees, but the difference was only statistically significant in 2 of 4 years (1995 and 2001).

Measurements of total, shoot, and spur leaf area per tree, spur number per tree, and spur density expressed the same trends in different ways. 'Gala' had more spurs and greater spur leaf area per tree than 'McIntosh', but the two cultivars were similar in shoot leaf area per tree (Table 2). Spur density was significantly greater for 'Gala' than 'McIntosh' in only one of the five years data were collected (1995, Table 2). The YT had about the same total leaf area per tree as spindles. The YT had the highest values for spur number per tree, spur leaf area per tree, and spur density, and the lowest for shoot leaf area per tree, in each year, but the difference among systems was not always statistically significant. Kappel and Quamme (1993) also reported system effects on spur number but not LAI, in young trees. Spur density was unaffected by tree density in any of the 5 years spur counts were made. Total leaf area per tree declined slightly above 3000 trees/ha (Table 2), in keeping with the smaller tree canopies at this density (Table 1). The leaf area per tree found here is much lower than in reports from Italy (Sansavini and Corelli, 1992) 
Table 2. Mean total leaf area index (LAI), the proportion of total leaf area in shoot leaves, spur LAI, total leaf area per tree, spur and shoot leaf area per tree, and number of spurs per tree in 1995 ( $4^{\text {th }}$ leaf) and 1998 ( $7^{\text {th }}$ leaf) of 'Royal Gala' and 'Summerland McIntosh' apple trees in three training systems at five tree densities.

\begin{tabular}{|c|c|c|c|c|c|c|c|c|c|c|c|c|c|c|c|c|}
\hline & \multicolumn{2}{|c|}{ Total LAI } & \multicolumn{2}{|c|}{$\begin{array}{l}\text { Proportion of } \\
\text { total leaf area in } \\
\text { shoot leaves }\end{array}$} & \multicolumn{2}{|c|}{$\begin{array}{l}\text { Spur } \\
\text { LAI }\end{array}$} & \multicolumn{2}{|c|}{$\begin{array}{l}\text { Total leaf } \\
\text { area }\left(\mathrm{m}^{2}\right)\end{array}$} & \multicolumn{2}{|c|}{$\begin{array}{l}\text { Spur leaf } \\
\text { area }\left(\mathrm{m}^{2}\right)\end{array}$} & \multicolumn{2}{|c|}{$\begin{array}{l}\text { Shoot leaf } \\
\text { area }\left(\mathrm{m}^{2}\right)\end{array}$} & \multicolumn{2}{|c|}{$\begin{array}{c}\text { Number of } \\
\text { spurs per tree }\end{array}$} & \multicolumn{2}{|c|}{$\begin{array}{l}\text { Spur density } \\
\text { (no./ } / \mathrm{cm}^{2} \text { TCA) }\end{array}$} \\
\hline & 1995 & 1998 & 1995 & 1998 & 1995 & 1998 & 1995 & 1998 & 1995 & 1998 & 1995 & 1998 & 1995 & 1998 & 1995 & 1998 \\
\hline \multicolumn{17}{|l|}{ Training system $(n=40)$} \\
\hline Slender spindle & 0.77 & 0.88 & 0.56 & 0.49 & 0.32 & 0.46 & 3.79 & 4.41 & 1.61 & 2.27 & 2.18 & 2.14 & 194 & 292 & 15.1 & 13.8 \\
\hline Tall spindle & 0.73 & 0.86 & 0.53 & 0.46 & 0.33 & 0.49 & 3.56 & 4.25 & 1.62 & 2.39 & 1.94 & 1.85 & 187 & 322 & 15.9 & 15.8 \\
\hline Y trell & 0.85 & 0.80 & 0.42 & 0.30 & 0.49 & 0.55 & 4.15 & 3.94 & 2.42 & 2.75 & 1.73 & 1.20 & 266 & 335 & 21.1 & 17.6 \\
\hline $\mathrm{MSD}^{\mathrm{z}}$ & 0.18 & 0.28 & 0.09 & 0.10 & 0.12 & 0.20 & 0.96 & 1.28 & 0.63 & 0.88 & 0.67 & 0.64 & 67 & 160 & 3.9 & 9.0 \\
\hline \multicolumn{17}{|c|}{ Density (trees/ ha) $(\mathrm{n}=24)$} \\
\hline 1125 & 0.42 & 0.50 & 0.50 & 0.45 & 0.22 & 0.28 & 3.76 & 4.47 & 1.93 & 2.53 & 1.84 & 1.94 & 216 & 322 & 17.6 & 15.7 \\
\hline 1587 & 0.65 & 0.75 & 0.49 & 0.36 & 0.33 & 0.45 & 4.07 & 4.71 & 2.05 & 2.84 & 2.02 & 1.87 & 233 & 320 & 17.7 & 15.0 \\
\hline & 84 & 0.85 & 0.50 & 0.44 & 0.40 & 0.48 & 4.19 & 4.22 & 2.00 & 2.39 & 2.19 & 1.83 & 234 & 303 & 17.3 & 13.8 \\
\hline & 95 & 1.07 & 0.49 & 0.41 & 0.49 & 0.65 & 3.83 & 4.33 & 1.96 & 2.6 & 1.87 & 1.7 & 217 & 38 & 17.9 & 18.9 \\
\hline 322 & 1.07 & 1.05 & 0.53 & 0.42 & 0.48 & 0.64 & 3.31 & 3.26 & 1.48 & 1.98 & 1.83 & 1.28 & 178 & 256 & 16.3 & 15.3 \\
\hline $\mathrm{MSD}^{\mathrm{z}}$ & 0.10 & 0.16 & 0.09 & 0.11 & 0.07 & 0.13 & 0.60 & 0.97 & 0.38 & 0.83 & 0.51 & 0.56 & 37 & 121 & 4.0 & 6.3 \\
\hline \multicolumn{17}{|l|}{ Cultivar $(n=60)$} \\
\hline Royal Gala & 0.82 & $1.10 \mathrm{a}^{y}$ & $0.46 \mathrm{~b}$ & 0.35 & $0.43 \mathrm{a}$ & $0.71 \mathrm{a}$ & 3.97 & $5.48 \mathrm{a}$ & $2.13 \mathrm{a}$ & $3.50 \mathrm{a}$ & 1.84 & 1.98 & 246 & $414 \mathrm{a}$ & $18.7 \mathrm{a}$ & 17.5 \\
\hline Summerland McIntosh & 0.75 & $0.59 \mathrm{~b}$ & $0.55 \mathrm{a}$ & 0.48 & $0.33 \mathrm{~b}$ & $0.29 \mathrm{~b}$ & 3.69 & $2.92 \mathrm{~b}$ & $1.63 \mathrm{~b}$ & $1.44 \mathrm{~b}$ & 2.06 & 1.48 & 186 & $219 \mathrm{~b}$ & $16.0 \mathrm{~b}$ & 14.0 \\
\hline
\end{tabular}

${ }^{2}$ Minimum significant difference determined by Waller-Duncan K ratio $t$ test $(\mathrm{K}$ ratio $=100)$

${ }^{y}$ Cultivar means followed by different letters are significantly different at the $5 \%$ level.

and Washington state (Barritt, 1989), where tree growth may have been more vigorous than in our climate.

Summary. Planting density was the most influential factor of the three in this study, exerting early and significant effects on nearly all the response variables measured. As density increased, tree size decreased, but LAI and light interception increased. Reductions in incremental TCA were evident as early as the second year when density exceeded 3000 trees/ha (data not shown). A planting density of 1125 trees per ha on M.9 was clearly too low. The trees never filled their space, and much light fell unused onto the alleys. Both LAI (below 1) and light interception $(\approx 32 \%)$ were suboptimal after 10 years. If interception of $50 \%$ to $70 \%$ is considered optimal (Lakso and Robinson, 1997; Robinson, 1997; Verheij and Verwer, 1973; Wünsche and Lakso, 2000), spindles would need to be planted at a density of at least 2250 trees/ha and the YT at least 1800 trees/ha (at the rectangularity used here) under the conditions for growth typical of our region.

Training system determined tree shape but not overall tree size. Training system did not begin to exert any significant effects on light interception until the sixth leaf. The shoot bending involved in training for the YT appeared to encourage spur development, as evidenced by a greater number of spurs (significant in 3 of 5 years) and a lower proportion of total leaf area in shoot leaves (significant in 3 of 4 years). The YT trees had similar total leaf area to spindle trees, but intercepted more light, most likely because of a greater reach over the alleyways. The TS and SS showed very similar performance, differing only in height, spread, and per-plot weight of prunings.

The common observation that 'McIntosh' is less vigorous than 'Gala' was confirmed by records of TCA, final scion weight and pruning requirements. 'McIntosh' trees intercepted about the same amount of light as 'Gala', but tended to have a greater proportion of leaf area in shoot leaves, and a lower spur LAI.

\section{Literature Cited}

Barden, J.A. and R.P. Marini. 2001. Comparison of methods to express growth, size, and productivity of apple trees. J. Amer. Pomol. Soc. 55:251-256

Barritt, B.H. 1989. Influence of orchard system on canopy development, light interception and production of third-year Granny Smith apple trees. Acta Hort. 243:121-130.

Barritt, B.H. 2000. Selecting an orchard system for apples. Compact Fruit Tree 33:89-92.

Callesen, O. 1993. Influence of apple tree height on yield and fruit quality. Acta Hort. 349:111115.

Callesen, O. and P.S. Wagenmakers. 1989. Effect of tree density, tree height and rectangularity on growth, flowering, and fruit production. Acta Hort. 243:141-148.

Clayton-Greene, K.A. 1993. Influence of orchard management system on yield, quality and vegetative characteristics of apple trees. J. Hort. Sci. 68:365-376.

Corelli, L. and S. Sansavini. 1989. Light interception and photosynthesis related to planting density and canopy management in apple. Acta Hort. and canopy mant

Cripps, J.E.L., F. Melville, and H.I. Nicol. 1975. The relationship of Granny Smith apple tree growth and early cropping to planting density and rectangularity. J. Hort. Sci 50:291-299.

Ferree, D.C. 1992. Influence of mechanical root pruning and hedging on performance of apple trees in three management systems. Acta Hort. 322:191-198.

Hampson, C.R., F. Kappel, H.A. Quamme, and R.T. Brownlee. 1997. Varying density with constant rectangularity: Effects on apple tree performance and yield in three training systems. Acta Hort. 451:437-442.

Hampson, C.R., H.A. Quamme, F. Kappel, and R.T. Brownlee. 1998. Effects of apple tree density and training system on productivity. Compact Fruit Tree 31:72-76.

Hampson, C.R., H.A. Quamme, and R.T. Brownlee. 2002a. Canopy growth, yield and fruit quality of 'Royal Gala' apple trees grown for eight years in five tree training systems. HortScience 37:627-631.

Hampson, C., H. Quamme, and R. Brownlee. 2002b. Tree density or training system B what is important in apple orchard design? Compact
Fruit Tree 35:48-50

Hampson, C.R., H.A. Quamme, F. Kappel, and R.T. Brownlee. 2004. Varying density with constant rectangularity. II. Effects on apple tree yield, fruit size and fruit color development in three training systems over ten years. HortScience 39(3):507-511.

Jackson, J.E. 1989. World-wide development of high-density planting in research and practice. Acta Hort. 243:17-27.

Kappel,F. and H.A. Quamme. 1993. Orchard training systems influence early canopy development and light microclimate within apple canopies. Can. J. Plant Sci. 73:237-248.

Kuroda, H. and K. Chiba. 2000. Effect of planting density on flower bud formation of 'Starking Delicious' apple trees grafted on dwarfing and semi-dwarfing rootstocks. J. Japan. Soc. Hort. Sci. 69:298-307. [in Japanese, English summary]

Lakso, A.N. and T.L. Robinson. 1997. Principles of orchard systems management optimizing supply, demand and partitioning in apple trees. Act Hort. 451:405-415

Lakso, A.N., J.N. Wünsche, J.W. Palmer, and L. Corelli-Grappadelli. 1999. Measurement an modeling of carbon balance of the apple tree. HortScience 34:1040-1047.

Palmer, J.W. 1989. The effects of row orientation, tree height, time of year and latitude on light interception and distribution in model apple hedgerow canopies. J. Hort. Sci. 64:137-145.

Palmer, J.W. 1999. Light, canopies, fruit and dollars. Compact Fruit Tree 32:119-122.

Parry, M.S. 1978. Integrated effects of planting density on growth and cropping. Acta Hort. 65:91-100.

Pearce, S.C. 1953. Field experimentation with fruit trees and perennial plants. Tech. Comm. No. 23. Commonwealth Bureau of Horticulture and Plantation Crops, Cmnwlth. Agr. Bur., East Malling, Maidstone, Kent, U.K.

Robinson, T.L. 1997. Interaction of tree form and rootstock on light interception, yield and efficiency of 'Empire', 'Delicious' and 'Jonagold' apple trees trained to different systems. Acta Hort. 451:427-436.

Robinson, T.L. 2000. V-shaped apple planting systems. Acta Hort. 513:337-347.

Robinson, T.L., A.N. Lakso, and S. Hoying. 1989 Managing the Y-trellis system. American Frui Grower 109:14-16, 22-23.

Robinson, T.L., J. Wünsche, and A.N. Lakso. 1993. 
The influence of orchard system and pruning severity on yield, light interception, conversion efficiency, partitioning index and leaf area index. Acta Hort. 349:123-127.

Sansavini, S. and L. Corelli. 1992. Canopy efficiency of apple as affected by microclimatic factors and tree structure. Acta Hort. 322:69-77.

Sansavini, S. and L. Corelli Grappadelli. 1997. Yield and light efficiency for high quality frui in apple and peach high density planting. Acta Hort. 451:559-568.

Verheij, E.W.M. and F.L.F.A.W. Verwer. 1973 Light studies in a spacing trial with apple on a dwarfing and a semi-dwarfing rootstock. Scientia Hort. 1:25-42.

Vitrup Christensen, J. 1979. Effects of density, rectangularity and row orientation on apple trees, measured in a multivariated experimental design. Scientia Hort. 10:155-165.
Wagenmakers, P.S. 1991a. Planting systems for fruit trees in temperate climates. Crit. Rev. Plant Sci. 10:369-385.

Wagenmakers, P.S. 1991b. Simulation of light distribution in dense orchard systems. Agr. Forest Meteorol. 57:3-25.

Wagenmakers, P.S. and O. Callesen. 1989. Influence of light interception on apple yield and fruit quality relative to arrangement and tree height. Acta Hort. 243:149-159.

Wagenmakers, P.S. and O. Callesen. 1995. Light distribution in apple orchard systems in relation to production and fruit quality. J. Hort. Sci. 70:935-948

Wertheim, S.J. 1985. Productivity and fruit quality of apple in single-row and full-field planting systems. Scientia Hort. 26:191-208.

Wertheim, S.J., A. de Jager, and M.J.J.P. Duyzens. 1986. Comparison of single-row and multi- row planting systems with apple, with regard to productivity, fruit size and colour, and light conditions. Acta Hort. 160:243-258.

Wertheim, S.J., P.S. Wagenmakers, J.H. Bootsma, and M.J. Groot. 2001. Orchard systems for apple and pear: conditions for success. Acta Hort. 557:209-227.

Wittneben, U. 1986. Soils of the Okanagan and Similkameen valleys. MOE Tech. Rpt. 18. British Columbia Ministry of Environ., Victoria, B.C., Canada.

Wünsche, J.N. and A.N. Lakso. 2000. The relationship between leaf area and light interception by spur and extension shoot leaves and apple orchard productivity. HortScience 35:1202-1206

Wünsche, J.N., A.N. Lakso, T.L. Robinson, F. Lenz, and S.S. Denning. 1996. The bases of productivity in apple production systems: The role of light interception by different shoot types. J. Amer. Soc. Hort. Sci. 121:886-893. 